\title{
Responsabilidad civil, daños punitivos y propiedad intelectual
}

\author{
Civil liability, punitive damages \\ and intellectual property
}

\section{Eduardo Serrano Gómez*}

\section{RESUMEN}

La aplicación de la doctrina de los daños punitivos en el ordenamiento juridico español no ha sido objeto, hasta ahora, de los encendidos debates que, en cambio, si han generado otras figuras juridicas cuya implantación en España y en otros países también se pretende. Probablemente, la causa de esa aparente tranquilidad se debe a que la mayor parte de los tratadistas y estudiosos del tema se han inclinado por negar la posibilidad de su introducción en nuestro derecho, si bien existen opiniones, que no dudan en la conveniencia de su implantación y de su compatibilidad con las reglas tradicionales que sustentan nuestra responsabilidad civil. Partiendo de esa idea previa, el objetivo principal que persigue este estudio se centra en analizar si la teoría de los daños punitivos ha penetrado efectivamente en el ámbito del derecho civil español y, en particular, si podemos considerar que se encuentra recogida ya en la Ley de Propiedad Intelectual. Para ello, es necesario analizar los argumentos a favor y en contra de su introducción y, en particular, si su artículo 140 los prevé de manera implícita. Se hará referencia, asimismo, a la cuestión de los daños morales en este ámbito.

PALABRAS CLAVE: Propiedad intelectual, derecho de daños, responsabilidad civil, daños punitivos, defensa y protección del derecho de autor, daño moral.

\begin{abstract}
The application of the doctrine of punitive damages in the Spanish legal system has not been subject, until now, of the heated debates which, in contrast, have been generated by other legal institutions intended for implementation in Spain and other countries.

It is likely that this apparent absence of controversy is due to the fact that the majority of legal authors and researchers writing on this subject have tended to deny the possibility of its introduction into our legal system. However, some legal opinions on the matter doubt neither the benefits of its introduction nor its compatibility with the traditional frameworks which sustain our civil liability. Based on the previous idea, the main objective of the present study is to analyse whether the theory of punitive damages has effectively penetrated the area of Spanish civil law and, in particular, whether we can consider that it is covered in the nation's copyright laws. In service to this aim, it is necessary to analyse the arguments for and against its introduction and, in particular, whether Article 140 of the Copyright Act covers this implicitly. It will also make reference to the question of non-material damages in this area.
\end{abstract}

KEY WORDS: Intellectual property, tort law / right to damages, civil liability, punitive damages, defense and protection of copyright. Non-material damages.

\footnotetext{
* Artículo de investigación. Recibido el 20 de septiembre de 2018 y aceptado para su publicación el 3 de julio de 2019.

** Profesor titular de Derecho Civil en la Universidad Complutense de Madrid, España. (eduserrano@yahoo.com) orcid.org/0000-0002-3119-0439
} 


\section{SUMARIO}

1. Introducción

2. Consideraciones generales del artículo 140.2 TRLPI

3. Las consecuencias económicas negativas o la remuneración que se hubiera obtenido de haber autorizado la explotación

4. El daño moral

5. ¿Es posible afirmar la existencia de daños punitivos en el artículo 140.2 del TRLPI?

6. Conclusiones

\section{Introducción}

La mayor parte de los tratadistas y estudiosos de los daños punitivos han negado de manera sistemática su posible aplicación al ordenamiento jurídico español. Sin embargo, han existido opiniones relevantes, como las de los profesores Salvador Coderch y Reglero Campos, ${ }^{1}$ quienes no han dudado en sostener la conveniencia de su implantación y su compatibilidad con las reglas tradicionales sobre las cuales se asienta el régimen de la responsabilidad civil en España.

En efecto, la doctrina civilista mayoritaria considera que las indemnizaciones destinadas a reparar los daños causados deben cubrir exactamente el daño producido, sea este de carácter material o moral. Además, deben abarcar tanto el daño emergente como el lucro cesante, pero sin que se pueda reconocer un quantum superior, el cual ha de incluir o reconocer otros extremos que no queden debidamente acreditados dentro del perjuicio sufrido.

En el sistema de responsabilidad civil europeo continental, y por tanto en el español, lo que se pretende es colocar a quien ha sufrido un daño en la misma posición que se encontraba antes de sufrir el perjuicio. Por ello, hablamos de la función compensatoria o reparadora de la responsabilidad civil, frente a lo que ocurre en los países de common law, donde se incluyen otras funcionalidades, además de la apuntada. Estas habilitan al juez para establecer cuantías indemnizatorias de mayor envergadura y que pueden sobrepasar con creces el valor del daño causado. En España, por lo tanto, la misión principal de la responsabilidad civil es la resarcitoria, mientras que, por la vía de los daños punitivos (o punitive damages), se consigue incluir además la sancionadora y la preventiva.

\footnotetext{
1 Reglero Campos, Luis Fernando, "Conceptos generales y elementos de delimitación", en Tratado de Responsabilidad Civil, Thomson-Aranzadi, Navarra, 2008, pp. 47 y ss.; y Salvador Coderch, Pablo, "Punitive Damages", InDret, 1/2000, pp. 2 y ss.
} 
A pesar de esta realidad incuestionable, se ha querido ver cómo nuestro legislador, en casos muy concretos, aparenta haberse colocado en una posición no del todo contraria al reconocimiento de los daños punitivos. Así, utiliza, por ejemplo, el criterio del beneficio obtenido por el responsable de la infracción para determinar el montante de la indemnización. Así ha ocurrido en el artículo 9.3 de la Ley Orgánica 1/1982, de 5 de mayo, sobre protección civil del derecho al honor, a la intimidad personal y familiar y a la propia imagen. También en el artículo 140.2 del texto refundido de la Ley de Propiedad Intelectual 1/1996 (en adelante TRLPI).

Partiendo de estas ideas previas, el objetivo principal de este estudio es analizar si la teoría de los daños punitivos ha penetrado efectivamente en el ámbito del derecho civil español. En particular, se busca responder si podemos considerar que esta teoría ya se encuentra recogida en el TRLPI, cuyo artículo 140.2 establece lo siguiente:

La indemnización por daños y perjuicios se fijará, a elección del perjudicado, conforme a alguno de los criterios siguientes: a) Las consecuencias económicas negativas, entre ellas la pérdida de beneficios que haya sufrido la parte perjudicada y los beneficios que el infractor haya obtenido por la utilización ilícita. En el caso de daño moral procederá su indemnización, aun no probada la existencia de perjuicio económico. Para su valoración se atenderá a las circunstancias de la infracción, gravedad de la lesión y grado de difusión ilícita de la obra. b) La cantidad que como remuneración hubiera percibido el perjudicado, si el infractor hubiera pedido autorización para utilizar el derecho de propiedad intelectual en cuestión.

\section{Consideraciones generales del artículo $140.2 \mathrm{TRLPI}$}

El artículo 140 del TRLPI, cuya actual redacción es consecuencia de la Ley 19/2006, de 5 de junio, por la que se amplían los medios de tutela de los derechos de propiedad intelectual e industrial y se establecen normas procesales para facilitar la aplicación de diversos reglamentos comunitarios, fija los elementos por observar para fijar el importe de la cuantía de la indemnización que corresponde por infracciones de derechos de propiedad intelectual. Esta reforma, a su vez, es consecuencia de la Directiva comunitaria 2004/48/CE del Parlamento Europeo y del Consejo, de 29 de abril de 2004, relativa al respeto de los derechos de propiedad intelectual, conocida popularmente con el nombre de directiva antipiratería. 
La regla general del artículo 140 del TRLPI es que la acción de indemnización por daños y perjuicios comprende no solo el valor de la pérdida que se haya sufrido, sino también el beneficio que se haya dejado de obtener como consecuencia de la infracción del derecho de propiedad intelectual. Esto es, daño emergente y lucro cesante, en la línea de lo estipulado en el artículo 1106 del Código Civil español: "La indemnización de daños y perjuicios comprende, no sólo el valor de la pérdida que hayan sufrido, sino también el de la ganancia que haya dejado de obtener el acreedor". Además, se pueden incluir los gastos de investigación en los que se haya incurrido con el objeto de obtener pruebas del ilícito cometido, siempre y cuando estos sean razonables, aunque no hayan arrojado un resultado positivo.

El perjudicado, por su parte, podrá elegir entre la reparación de las consecuencias económicas negativas que la infracción le haya supuesto, con inclusión de los posibles daños morales, o bien reclamar la cantidad que hubiera percibido del infractor como remuneración, en caso de que hubiera pedido autorización para utilizar la obra protegida. Si lo desea, también podrá solicitar al juez que tome en consideración, de forma alternativa, el criterio que le resulte más favorable a sus intereses.

Del análisis del articulado del TRLPI se extrae que, en principio, el legislador ha querido reservar la existencia de daños patrimoniales a los supuestos de contravención de los derechos patrimoniales. Mientras, los daños morales quedarian restringidos para aquellos casos donde los que han resultado quebrantados son derechos de naturaleza moral. Sin embargo, debe quedar claro que, a pesar de esa dualidad que impregna la regulación apuntada, es perfectamente posible que se produzcan daños morales derivados de infracciones patrimoniales y, a la inversa, daños patrimoniales por consecuencia de la lesión de un derecho moral.

Como indica Clemente Meoro, ${ }^{2}$ si solo se solicita indemnización por daño patrimonial, no cabe concederla por daño moral, y a la inversa, si únicamente se solicitó daño moral, no cabe condena por daño patrimonial. Ahora bien, ambas indemnizaciones pueden ser solicitadas al mismo tiempo, en caso de probar la existencia de ambas tipologías de daños y al ser debidamente separadas en el pronunciamiento judicial que se dicte al respecto.

${ }^{2}$ Clemente Meoro, Mario Enrique, "Comentario al art. 140 trlpl", en Comentarios a la Ley de Propiedad, Intelectual, Thomson-Civitas, Madrid, 2007, p. 810. 


\section{Las consecuencias económicas negativas o la remuneración que se hubiera obtenido de haber autorizado la explotación}

En la valoración del daño sufrido como consecuencia de una infracción a los derechos de propiedad intelectual, se pueden tomar en consideración los siguientes elementos: el perjuicio patrimonial sufrido, la cantidad que se hubiera obtenido de haber autorizado el comportamiento que contraviene el derecho comprometido, y el beneficio que el infractor haya obtenido. ${ }^{3}$

En efecto, el TRLPI tiene en cuenta tales factores, aunque en realidad se encuentran agrupados en dos modalidades específicas. Así, las posibilidades que se le plantean a quien sufre el daño son, por un lado, optar por el perjuicio efectivamente sufrido -las consecuencias económicas negativas provocadas por la actividad del infractor-, o bien decantarse por la remuneración que hubiera obtenido de haber autorizado la explotación. La primera opción no parece plantear demasiados problemas, pues se ajusta a las reglas generales de la reparación del daño. Sin embargo, como luego veremos, las dudas se plantean respecto de los beneficios obtenidos por el infractor como elemento para el cómputo de la indemnización.

En todo caso, se debe tener en cuenta que ambas posibilidades de indemnización son alternativas e incompatibles entre sí. Por ello, se precisa un especial cuidado en la elección que pueda resultar más ventajosa pues la desestimación de la pretensión indemnizatoria por una de las vías cerraría la eventualidad de recurrir a la otra, salvo que, como se ha apuntado ya, el perjudicado manifieste expresamente y por adelantado que optará por el criterio que le resulte más beneficioso.

\section{a) Las consecuencias económicas negativas}

Esta primera modalidad es la que se ajusta a priori a las reglas generales de la responsabilidad civil en España, pues pretende el resarcimiento del daño real y efectivo sufrido por el titular de los derechos de propiedad intelectual como consecuencia de la actividad infractora. Ello incluye la pérdida de beneficios; no solo el daño emergente, sino también el lucro cesante. Nótese que se habla de "las consecuencias económicas negativas" sufridas, es decir, del perjuicio total que se haya causado al titular de los derechos de propiedad intelectual como consecuencia de la conducta infractora.

\footnotetext{
${ }^{3}$ BASOZABAL, XABIER, "Método triple de cómputo del daño: la indemnización del lucro cesante en las leyes de protección industrial e intelectual", $A D C, 1997$, p. 1265.
} 
Sin embargo, el asunto se complica cuando, para la determinación del perjuicio sufrido, se incluyen como elemento valorativo "los beneficios que el infractor haya obtenido por la utilización ilícita”. Podríamos pensar que el legislador incluye la referencia a este factor en la medida en que podría quedar implicado en el lucro cesante del perjudicado.

El fundamento por el cual se refieren los beneficios que obtiene el infractor es que tal lucro podría haberlo sido para el perjudicado y, por tanto, integran la partida del lucro cesante que ha de tenerse en cuenta a la hora de fijar la indemnización. Igualmente, se podría sostener que el criterio del beneficio obtenido por el infractor concuerda más con la doctrina del enriquecimiento injusto, pues beneficia claramente al perjudicado en la medida en que no se exigiría necesariamente la presencia de un daño ni acreditar la existencia de dolo o culpa. Por tanto, en aquellos supuestos en los que no se haya producido un daño directo, aunque sí un cierto empobrecimiento, podríamos admitir las posibilidades restitutorias que ofrece el enriquecimiento injusto, al margen de las medidas puramente indemnizatorias que contempla la ley. Todo ello teniendo en cuenta la compatibilidad de la acción indemnizatoria con una acción de enriquecimiento injusto.

Ya la directiva antipiratería del año 2004 recogía esa posibilidad en el artículo 13.2, si bien el legislador español decidió no introducirla en la Ley de 2006. En efecto, la directiva establecía que "cuando el infractor no hubiere intervenido en la actividad infractora a sabiendas ni con motivos razonables para saberlo, los Estados miembros podrán establecer la posibilidad de que las autoridades judiciales ordenen la recuperación de los beneficios o el pago de los daños y perjuicios que podrán ser preestablecidos”. Con ello, se podían resolver casos específicos en los que la reparación del daño sufrido por el perjudicado seguiría sin alcanzar el beneficio que el infractor hubiere obtenido por medio de su conducta.

En definitiva, las opciones teóricas que tendría el perjudicado en su mano serían tres: indemnización que compense el daño sufrido (daño real); reclamación

134 de lo que el perjudicado hubiera obtenido de haber autorizado la explotación, y, por la vía del enriquecimiento injusto, solicitar la restitución de los beneficios obtenidos por el infractor. Estos, como es lógico, no tienen por qué coincidir con el lucro que haya dejado de obtener el titular de los derechos.

En mi opinión, a pesar de las evidentes conexiones, realmente no se debe considerar que la ley está reconociendo una especie de acción de enriquecimiento injusto, cuando el beneficio del infractor equivale al que hubiera obtenido el titular de derechos, de haber llevado a cabo esa explotación. Simplemente, tales elementos constituyen indicadores para modular la indemnización que 
se ha de reconocer al perjudicado, permitiendo una mejor y mayor adaptación al daño que se haya sufrido.

En cualquier caso, será el juez quien deberá valorar esas consecuencias negativas, así como el beneficio obtenido por el infractor. Para ello, puede tomar en cuenta cualquier otra variable que considere oportuna, pues el artículo 140 del TRLPI alude a título meramente indicativo - "entre ellas" señala literalmentesolo a la pérdida de beneficios que haya sufrido la parte perjudicada y a los beneficios que el infractor haya obtenido por la utilización ilícita, sin cerrar la puerta a otros criterios cuya utilidad quede acreditada para la más adecuada resolución del asunto.

\section{b) La remuneración que se hubiera percibido}

La segunda posibilidad que contempla el artículo 140 del TRLPI se limita al perjuicio sufrido por el titular de los derechos, atendiendo a las ganancias que el infractor ha obtenido al ahorrarse la solicitud de autorización con la cual debía haber contado. Es decir, por esta vía no sería necesario constatar el daño efectivamente sufrido, sino únicamente proceder a la valoración de cuanto hubiera supuesto la autorización de la conducta infractora del derecho de autor afectado. El objetivo que se pretende es claro: evitar el enriquecimiento de quien infringe derechos de propiedad intelectual, salvándose, por otra parte, los tradicionales obstáculos que nuestros tribunales han manifestado en la acreditación del lucro cesante.

A la hora de fijar la cuantía de la remuneración se tendrán en cuenta elementos fácticos, tales como el valor de mercado, ${ }^{4}$ anteriores licencias, o las tarifas aprobadas por las entidades de gestión. También es cierto que la indemnización así contemplada podrá tomar en consideración otros elementos, por ejemplo, el daño moral u otros perjuicios. De lo contrario, colocaríamos al infractor en una posición claramente ventajosa, pues le daría lo mismo solicitar la autorización antes de la comisión de la actividad infractora que asumir una indemnización a posteriori que solo tuviera en cuenta el precio de aquella. Ahora bien, el legislador no incluye expresamente ningún elemento que permita una sanción extra al infractor ni acercarnos a la órbita de los daños punitivos.

Por otra parte, no queda claro si es posible aplicar esta opción del dañoregalía a aquellos titulares de derechos que, reiteradamente, han manifestado

\footnotetext{
${ }^{4}$ Lobato Garcia Mujàn, M., "La protección de los derechos de propiedad intelectual en la jurisdicción civil", en Propiedad intelectual: aspectos civiles y penales, Madrid, Consejo General del Poder Judicial, 2008, p. 123.
} 
su negativa a ofrecer autorizaciones para la explotación de las obras cuyos derechos son objeto de controversia. El legislador es claro al permitir ambas alternativas, sin hacer distinciones según las peculiaridades de cada caso. Sin embargo, no parece razonable que se acuda a esta vía cuando, por negativas continuadas a otorgar licencias, no pueda determinarse el precio que se hubiera obtenido de haber obtenido la autorización. Salvo que este pueda acreditarse de alguna manera, entiendo que queda gravemente debilitada la posibilidad de que el juez admita esta segunda modalidad de reparación.

Por tanto, parece que, a pesar del carácter alternativo de los dos mecanismos determinantes de la indemnización que recoge el artículo 140.2 del TRLPI, en mi opinión, la tendencia debería ser la de fomentar el primero de ellos frente al segundo. Este debería quedar relegado a un medio subsidiario cuando sea imposible determinar el perjuicio efectivamente sufrido. De esta manera, nos estaríamos ajustando mejor a los postulados básicos de nuestro sistema sobre responsabilidad civil.

En todo caso, no porque debe se proceda al pago de la regalía que se hubiera exigido de haber sido autorizada la actividad infractora la conducta del infractor queda convalidada, ni este adquiere derecho alguno para emprender una explotación lícita de la obra.

\section{El daño moral}

Según el artículo 140 del TRLPI, procederá la indemnización del daño moral, aunque no exista perjuicio económico. Para su determinación, se valorarán las circunstancias de la infracción, la gravedad de la lesión y el grado de difusión ilícita de la obra. El juez podrá tener en cuenta aquellos otros elementos que considere oportunos, pues serán fácilmente reconducibles al criterio de "las circunstancias de la infracción”.

La ubicación sistemática en el TRLPI del apartado relativo a los daños morales parece dar a entender que serán exigibles e indemnizables únicamente

136 cuando se opte por la primera de las dos modalidades indemnizatorias que se apuntaron anteriormente. Tal interpretación es errónea, pues, como es lógico, siempre que exista daño moral será resarcible y este puede darse tanto en conjunto con el daño material como en su ausencia. No obstante, la utilización de los daños morales se presenta como una alternativa especialmente eficaz para la compensación de los perjuicios sufridos como consecuencia de una infracción de los derechos morales recogidos en el artículo 14 del TRLPI; en particular, cuando no se haya derivado una consecuencia económica negativa y directa. 
En el caso de los daños morales, Delgado Porras señala: "más que de una indemnización, se trata de una reparación o compensación pecuniaria a la agresión sufrida por el autor o el artista en su personalidad (pretium doloris) por causa de la infracción". ${ }^{5}$ En cambio, cuando se trate de infracciones de los derechos patrimoniales, que sí pueden fácilmente ser convertidos a términos monetarios, el recurso a los daños morales será más complicado. Por ello, quedan reservados a aquellos supuestos en los que la violación patrimonial provoca un perjuicio dentro de la esfera personal o íntima del titular de los derechos, lo cual no parece que pueda darse con frecuencia.

En materia de propiedad intelectual, Carrasco Perera ${ }^{6}$ indica que el recurso a los daños morales suele perseguir dos objetivos. Por un lado, este recurso sirve de cauce para compensar al titular del derecho, cuando el daño es evidente, pero de difícil cuantificación y no es susceptible de una determinación de modo directo. Por otro lado, funciona como mecanismo para "castigar las conductas infractoras o desincentivar prácticas futuras del mismo estilo”, es decir, como sistema sancionador o preventivo. Precisamente, en esta segunda perceptiva es donde obtiene especial relevancia la consideración de "las circunstancias de la infracción, la gravedad de la lesión y grado de difusión ilícita de la obra", elementos que se tendrán en cuenta para "castigar" en mayor o menor medida al agente del daño.

En cambio, en la determinación del daño moral no se incluye, como criterio para su fijación, el beneficio que haya obtenido el infractor, aunque podría quedar incluido en las circunstancias genéricas en que la infracción ha tenido lugar. No consta, por tanto, un elemento que nos permita hablar de la existencia de una función punitivo-sancionadora. Ahora bien, en la práctica, los daños morales son utilizados para introducir una cierta sanción al agente infractor. Por ello, los países anglosajones, mucho más reacios al reconocimiento de este tipo de daño, optan por los punitive damages como mecanismo para castigar la conducta ilícita.

Por último, es preciso recordar que, como señala Bércovitz Álvarez, ${ }^{7}$ el reconocimiento de un daño moral indemnizable no siempre proviene de una explotación ilícita, pues puede llegar a resultar, por ejemplo, de una lesión al corpus mechanicum de la obra (soporte) y no al corpus mysticum (creación).

\footnotetext{
${ }^{5}$ Delgado Porras, Antonio, Panorámica de la protección civil y penal en materia de propiedad intelectual, Madrid, Civitas, 1988, p. 95.

${ }^{6}$ Carrasco Perera, Ángel, "Comentario al art. 140 trlpi", en Comentarios a la ley de Propiedad Intelectual, Madrid, Tecnos, 2017, pp. 1867 y ss.

7 Bercovitz Álvarez, Germán, "Protección de los derechos de propiedad intelectual", en Manual de Propiedad Intelectual, Valencia, Tirant lo Blanch, 2017, p. 347.
} 


\section{5. ¿Es posible afirmar la existencia de daños punitivos en el artículo 140.2 del TRLPI?}

Teniendo en cuenta las consideraciones que se han hecho en las líneas que anteceden, sesurge como plantea como principal duda si es posible lograr una hipotética compatibilidad entre el reconocimiento de unos daños punitivos en el ámbito de la propiedad intelectual y nuestro tradicional derecho de daños. Ello en el contexto de que se exige la prueba del perjuicio sufrido y cuya finalidad principal es la puramente resarcitoria, de tal manera que la indemnización debe ser equivalente al daño sufrido y este ha de probarse convenientemente. En consecuencia, en derecho español, parece imposible admitir el reconocimiento de una indemnización a favor del perjudicado sin necesidad de probar el daño y de una cuantía que pueda exceder lo que este realmente supone.

Sin embargo, se ha querido interpretar que el artículo 140.2 del TRLPI presenta un cierto acomodo a la doctrina de los daños punitivos, pues, como instrumento sancionador, permite teóricamente el reconocimiento de una cantidad indemnizatoria que puede situarse por encima de la requerida para compensar estrictamente el perjuicio sufrido por el titular de los derechos de propiedad intelectual. Ello daría lugar a que, debido a la conducta intolerable del infractor, ciertos daños sean resarcibles sin necesidad de probar su existencia. Así, se justificaría este tipo de medidas con que la infracción del derecho puede provocar más beneficios al infractor que perjuicios al titular del derecho.

De tal modo, la indemnización meramente compensatoria no supondría apenas carga o gravamen alguno para aquel.

Los daños punitivos permitirían entonces la imposición de una indemnización abstracta, restándole importancia a si los motivos de su establecimiento se deben a la existencia directa de un hecho ilícito o si responden a la tipología de una restitución por enriquecimiento. Por tanto, lo único que habría que probar sería que, efectivamente, se ha vulnerado un derecho de propiedad intelectual y ello sería suficiente para tener derecho a la indemnización del artículo 140 del TRLPI.

En este sentido, precisamente la Directiva comunitaria 2001/29/CE, que regula las sanciones y vías de recurso en materia de propiedad intelectual, señala: "las sanciones deberán ser efectivas, proporcionadas y disuasorias". Por tanto, acoge una finalidad claramente preventiva en la protección de estos derechos. De manera similar, el Acuerdo sobre los Aspectos de los Derechos de Propiedad Intelectual relacionados con el Comercio de 15 de abril de 1994 (ADPIC) prevé la "inclusión de recursos ágiles para prevenir las infracciones y de recursos que constituyan un medio eficaz de disuasión de nuevas infracciones”. 
En efecto, con disposiciones de este tenor sería posible entender la existencia de una vía para el establecimiento de los daños punitivos y para su reconocimiento en los países europeos.

De manera similar, la directiva antipiratería de 2004 permitía la incorporación solapada de los daños punitivos, pues aludía a una cantidad a tanto alzado sobre la base del importe de los cánones o derechos que le adeudarían a su titular en caso de que el infractor hubiera pedido autorización. En consecuencia, esa posibilidad daba lugar a indemnizaciones determinadas con múltiplos del importe de dichos cánones o derechos. Sin embargo, el legislador español no toma en cuenta tales previsiones, lo cual se puede interpretar como un rechazo a la posibilidad de los daños punitivos.

Señalan Yzquierdo Tolsada y Arias Maíz ${ }^{8}$ que "quizá el legislador hubiese sido más explícito al permitir la introducción de daños punitivos en nuestro ordenamiento jurídico (o, en general, en el de todos los ordenamientos jurídicos de la Unión Europea) si fuese consciente de que, de introducirse esa figura, se estaría creando un precedente peligroso para su generalización a otras ramas de la responsabilidad civil".

En mi opinión, cuando el artículo 140 del TRLPI alude a las ventajas o ganancias obtenidas por el infractor, lo que persigue realmente es compensar al titular de los derechos vulnerados cuando los beneficios obtenidos sean superiores al daño concreto sufrido. Pero tal objetivo tiene un planteamiento distinto al de los daños punitivos, aun cuando puedan existir ciertas conexiones o interferencias. De hecho, la alusión a esos beneficios no se prevé como una medida de carácter sancionador o ejemplarizante, sino restitutorio. Es decir, se refiere a reorganizar las atribuciones patrimoniales que ha sufrido el causante del daño como consecuencia de su infracción. Estas han de retirarse de su patrimonio para reingresarlas al del perjudicado, quien debiera haberlas obtenido desde el principio. Ello, como se ha dicho anteriormente, nos lleva más a la órbita de la teoría del enriquecimiento injusto que a la de los daños punitivos.

De este modo, la posibilidad de reclamar como parte de la indemnización el beneficio obtenido por el infractor constituye un factor para la mejor determinación de las consecuencias económicas negativas sufridas, y no tanto una sanción de carácter preventivo o disuasorio. Es verdad que ese beneficio es un concepto independiente del daño efectivamente sufrido por el titular de los derechos, lo cual nos acerca al concepto de pena privada. Este parece revestir un matiz de

${ }^{8}$ Yzouierdo Tolsada, Mariano y Arias Maiz, Vicente, "Responsabilidad civil por daños a la propiedad intelectual", Tratado de Responsabilidad Civil, Navarra, Thomson - Aranzadi, 2008, p. 629. 
punición destinado a frustrar cualquier ventaja obtenida por el infractor como consecuencia de su actuación fraudulenta. Sin embargo, su inclusión dentro de "las consecuencias económicas negativas" sufridas por el titular de los derechos nos aleja de esa idea y nos acerca a la conclusión de que tal criterio se encuentra previsto únicamente como medio para concretar los beneficios que el perjudicado hubiera obtenido de haber autorizado la conducta ilícita. Esto último sí quedaría incluido en el concepto de lucro cesante. ${ }^{9}$

En esa línea, Yzquierdo Tolsada y Arias Maíz ${ }^{10}$ señalan que:

Cuando se habla de pena privada o de daños punitivos, si algo hay es una porción de la indemnización que se viene a añadir a la puramente compensatoria, en forma de castigo ejemplarizante o disuasorio. Y criterios que lo permitan expresamente no parece que los hubiera en la versión del art. 140 , párr. $2^{\circ}$ anterior a la reforma de 2006. Otra cosa es que el amplio arbitrio judicial permita en cada caso engordar las cifras para obtener semejante resultado.

Abundando en esa idea, los autores destacan que, cuando el artículo 140 del TRLPI hace referencia a los beneficios ilícitos obtenidos por el infractor, no está diciendo que pueda reclamarlos para sí, sino únicamente que serán tenidos en cuenta por el juez a la hora de determinar la indemnización. ${ }^{11}$

En ese sentido, si admitiéramos los daños punitivos, sería necesario efectuar una reinterpretación de la labor del juez a la hora de fijarlos. Lo lógico sería que se ajustara a ciertos parámetros y que no poseyera una plena libertad para determinar su cuantía. En mi opinión, en caso de ser aceptados, los daños punitivos requeririan una importante labor de control para evitar supuestos en los que provoquen un flagrante enriquecimiento injusto de quien los recibe. Asimismo, deberían guardar cierta proporción con el daño efectivamente causado al titular de los derechos, para evitar una arbitrariedad en su concesión y la adquisición de un importe a todas luces excesivo.

Del mismo modo, podemos objetar a los daños punitivitos la falta de garantías que supondría la aplicación de una pena sin las garantías que existen en los procesos penales. Resarcimiento y pena en el mismo proceso civil no parecen lo

\footnotetext{
${ }^{9}$ BASOZABAL, XABIER, "Método triple de cómputo del daño: la indemnización del lucro cesante en las leyes de protección industrial e intelectual", $A D C, 1997$, p. 1297.

${ }^{10}$ Yzoulerdo Tolsada, Mariano y Arias Maiz, Vicente, "Responsabilidad civil por daños a la propiedad intelectual", Tratado de Responsabilidad Civil, Navarra, Thomson - Aranzadi, 2008, p. 612.

${ }^{1}$ Yzouierdo Tolsada, Mariano y Arias Maiz, Vicente, "Responsabilidad civil por daños a la propiedad intelectual", Tratado de Responsabilidad Civil, Navarra, Thomson - Aranzadi, 2008, p. 614.
} 
más adecuado para garantizar los derechos del infractor de los derechos. Además, las infracciones de derechos contra la propiedad intelectual constituyen tipos penales que aparecen contemplados en el Código Penal y, por tanto, pueden ser perfectamente sancionados, penados y prevenidos por esa vía.

\section{Conclusiones}

Sin demasiados reparos, se puede concluir que, en la actualidad, sigue sin haberse alterado uno de los pilares fundamentales sobre los cuales se asienta la responsabilidad civil en España: la indemnización alcanza a todo el daño, pero a nada más que al daño. El tenor literal del artículo 140 del TRLPI recoge una forma de determinar la indemnización que es evidentemente discutible, pero que tiende a la protección del perjudicado. Son los tribunales los que, a la vista de los hechos, las circunstancias concurrentes y las pruebas practicadas, fijarán el quantum de la indemnización que en cada supuesto corresponda. ${ }^{12}$ Por ello, se debe efectuar una lectura indemnizatoria-restitutoria de las ganancias obtenidas por el infractor, en lugar de punitiva-preventiva, orientada a un resarcimiento total de la víctima.

Aunque el texto literal del artículo 140.2 del TRLPI pueda incluir aspectos ajenos a la función compensatoria de la responsabilidad civil y a la realidad del daño causado, en rigor, todavía no se puede hablar de daños punitivos en el ámbito de la propiedad intelectual. Se puede afirmar que la intención del legislador, incluso tras la reforma efectuada en el año 2006, no fue la de introducir un elemento punitivo sancionatorio de la conducta del infractor de los derechos de propiedad intelectual.

Teniendo en cuenta que los daños punitivos persiguen un triple objetivo -el sancionador, el preventivo y el destinado a eliminar el beneficio indebidamente obtenido por el causante del daño-, la pregunta es clara: ¿son esos los fines que persigue el artículo 140 del TRLPI, en particular al referir los "beneficios obtenidos por el infractor"? La respuesta, en mi opinión, ha de ser claramente negativa. No parece que haya una finalidad preventiva ni sancionadora en tal elemento valorativo; lo que se pretende es una más ajustada determinación de la indemnización reparadora del daño sufrido por el titular de los derechos de propiedad intelectual.

Con todo, dada la actual preocupación respecto a la necesaria protección de los derechos de los creadores, no debería obviarse el debate en torno a los daños punitivos en este ámbito. La práctica diaria demuestra cómo, en muchos

\footnotetext{
${ }^{12}$ Véase, Vega Vega, José Antonio, Protección de la propiedad intelectual, Madrid, Reus, 2002, p. 399.
} 
casos, sigue siendo más lucrativo el infringir derechos de esta naturaleza que hacer frente a las indemnizaciones que se fijan. Quizá, en el futuro, debería admitirse la existencia de daños punitivos en supuestos de carácter excepcional donde la conducta del agente causante del daño sea especialmente intolerable, por ejemplo, por ser claramente dolosa, temeraria o estar revestida de una indudable mala fe.

\section{Bibliografía}

Basozabal, Xabier, "Método triple de cómputo del daño: la indemnización del lucro cesante en las leyes de protección industrial e intelectual”, $A D C, 1997$, pp. 1263 y ss.

Bercovitz Álvarez, Germán, "Protección de los derechos de propiedad intelectual”, en Manual de Propiedad Intelectual, Valencia, Tirant lo Blanch, 2017, pp. 337 y ss. Carrasco Perera, Ángel, "Comentario al art. 140 trlpi", en Comentarios a la Ley de Propiedad Intelectual, Madrid, Tecnos, 2017, pp. 1855 y ss.

Clemente Meoro, Mario Enrique, “Comentario al art. 140 trlpi”, en Comentarios a la Ley de Propiedad, Intelectual, Thomson-Civitas, Madrid, 2007, pp. 805 y ss.

Delgado Porras, Antonio, Panorámica de la protección civil y penal en materia de propiedad intelectual, Madrid, Civitas, 1988.

Lobato García Miján, M., "La protección de los derechos de propiedad intelectual en la jurisdicción civil”, en Propiedad intelectual: aspectos civiles y penales, Madrid, Consejo General del Poder Judicial, 2008, pp. 113 y ss.

Reglero Campos, Luis Fernando, “Conceptos generales y elementos de delimitación”, en

Tratado de Responsabilidad Civil, Thomson-Aranzadi, Navarra, 2008, pp. 47 y ss. Salvador Coderch, Pablo, "Punitive Damages", InDret, 1/2000, pp. 2 y ss.

Vega Vega, José Antonio, Protección de la propiedad intelectual, Madrid, Reus, 2002. Yzquierdo Tolsada, Mariano y Arias Maíz, Vicente, "Responsabilidad civil por daños a la propiedad intelectual", Tratado de Responsabilidad Civil, Navarra, Thomson - Aranzadi, 2008, pp. 529 y ss. 